\title{
Применение Инновационных Технологий в Производстве Помадных Конфет
}

\author{
Л.В. Зайцева ${ }^{\text {a) }}$ Т.В. Баулина, Ю.А. Ускова, М.А. Пестерев и А.И. Акимов \\ Author Affiliations \\ ${ }^{1-5}$ Всероссийский научно-исследовательский институт кондитерской промышленности (ВНИИКП) - \\ филиал ФГБНУ «ФНЦ пищевых систем им. В.М. Горбатова» РАН, 107023, ул. Электрозаводская 20 стр.3, \\ Москва, Россия \\ Author Emails \\ a) Corresponding author: conditerprom@mail.ru
}

\begin{abstract}
Аннотация. Изучены изменения физико-химических и органолептических свойств неглазированных сливочных помадных конфет, обусловленные заменой крахмальной патоки на инвертные сиропы. Кислый инвертный сироп (IS) и инвертный сироп с применением кавитационной обработки (IS ${ }_{\text {cav }}$ ) получали по разработанным во ВНИИКП технологиям. С применением стандартных методов исследованы плотность, динамическая вязкость, активность воды в инвертных сиропах и помадных сиропах на их основе. Изучена микроструктура помадных масс и изменение массовой доли влаги в процессе хранения готовых изделий. Установлено, что использование $\mathrm{IS}_{\text {cav }}$ в рецептуре дает наилучшие результаты. Применение кавитации при производстве инвертного сиропа позволяет получать продукт со 100-ной инверсией сахарозы, влажностью 20\%, с дисперсностью среды 0,2-0.4 Mкм. $\mathrm{IS}_{\text {cav }}$ по сравнению c IS имеет более высокие показатели динамической вязкости, активности воды, и меньшую плотность. Увеличение дисперсности системы приводит к лучшему удержанию влаги помадными конфетами в процессе их хранения (35 сут, $5{ }^{\circ} \mathrm{C}$, негерметично) при соблюдении допустимых нормативных показателей микробиологической безопасности. Помадные конфеты на IS $_{\text {cav }}$ характеризуются мелкокристаллической текстурой, что обеспечивает им более нежную, таящую во рту консистенцию по сравнению с изделиями на патоке.
\end{abstract}

Ключевые слова: помадные конфеты, инвертный сироп, кавитационная обработка, физико-химические показатели, хранение

\section{1. ВВЕДЕНИЕ}

Помадная масса является гетерогенной системой, в которой жидкая фаза представлена насыщенным раствором сахарозы в присутствии патоки, а твердая фаза представлена различными по величине кристаллами сахарозы. Одним из недостатков помадной конфетной массы является потеря влаги при хранении, что приводит к увеличению содержания твердой фазы или черствению. Реологические характеристики относятся $\mathrm{k}$ важнейшим физико-химическим показателям, определяющим качество кондитерских масс и особенности различных технологических процессов их переработки. Для получения продукции со стабильными качественными характеристиками необходимо учитывать особенности реологического поведения используемого сырья и полуфабрикатов. В настоящий момент известно три способа уменьшения скорости влагопереноса, один из которых заключается в увеличении упругости пара над жидкой фазой помадной массы с помощью таких добавок как инвертный сироп, яичный белок, фруктовое пюре или сочетанием всех трех компонентов.

Качество гетерофазных пищевых систем также зависит от их дисперсионных свойств. Применяя различные воздействия (ультразвуковые, электрические и магнитные поля, СВЧ и т.п.), можно изменять 
свойства пищевых систем [1-6]. Инновационным вектором развития в кондитерском производстве считается применением теории механо-химических процессов в смесях жидких и твердых фаз. Одним из таких процессов является кавитационная обработка.

«Кавитация - это образование в жидкой фазе пузырьков (каверн), заполненных паром, газом или их смесью. В ультразвуковой волне во время полупериодов разрежения возникают кавитационные пузырьки, которые резко схлопываются после перехода в область повышенного давления, порождая сильные гидродинамические возмущения в жидкости и интенсивное излучение акустических волн. При этом в дисперсной системе происходит разрушение твердых частиц, граничащих с кавитирующей жидкостью» [7].

Применение кавитационной обработки для изменения реологических свойств гетерофазных пищевых сред имеет официальное разрешение в Российской Федерации. Во Всероссийском научноисследовательском институте кондитерской промышленности разработаны и апробированы способы обработки гетерофазных пищевых систем с применением кавитационных воздействий [8-11].

Также специалистами института разработан способ получения кислого инвертного сиропа с применением кавитационной обработки. При этом, полученный инвертный сироп имеет практически однородную вязкую консистенцию с равномерной дисперсностью частиц [12]. Использование кавитационно обработанного инвертного сиропа открывает перспективы для разработки кондитерских изделий с увеличенным сроком годности и повышенными органолептическими и физико-химическими показателями.

Целью данной работы являлось изучение органолептических и физико-химических показателей помадных масс, полученных путем замены патоки на кислый инвертный сироп, прошедший кавитационную обработку.

\section{2. МАТЕРИАЛЫ И МЕТОДЫ}

Исследования проводились во Всероссийском научно-исследовательском институте кондитерской промышленности (ВНИИКП) - филиал ФГБНУ «ФНЦ пищевых систем им. В.М. Горбатова» РАН.

Для выполнения экспериментальной работы были выбраны сливочные помадные конфеты с неглазированными корпусами по рецептуре [13]. Основным сырьем для их производства являются сахар белый, молоко сгущенное с сахаром (жирность 8,5\%), масло сливочное (жирность 72,5\%), патока крахмальная.

В модельных образцах произведена замена крахмальной патоки на кислые инвертные сиропы, полученные по разработанным во ВНИИКП технологиям, с применением и без применения кавитационной обработки [7]. Расчет количества вносимого сиропа осуществляли с учетом соблюдения одинакового количества содержания сухих и редуцирующих веществ в контрольном и модельных образцах.

Кавитационную обработку сахарного сиропа осуществляли на лабораторной установке марки «Сиринкс 250-К» (ООО «Астор-С», РФ), в которой совмещены акустические и гидродинамические воздействия на жидкую среду.

Исследование динамической вязкости инвертных и помадных сиропов проводили на ротационном вискозиметре Rheotest RV5.1 («Messgerate Medingen GmbH», Германия) с использованием цилиндрического измерительного устройства.

Методика измерения плотности ( $\rho \dot{i}$ инвертных и помадных сиропов заключалась в измерении массы вещества ( $m i$ в заданном объеме $(v)$ с последующим расчетом по известной формуле.

Массовую долю влаги помадных масс определяли с помощью анализатора влажности MB-23 («OHAUS Corp.», США).

Активность воды инвертных и помадных сиропов определяли на приборе AquaLab 3TE («Decagon Devices, Inc.», США).

Анализ микроструктуры помадных масс проводили на цифровом микроскопе Bresser LCD 50x-2000x («Bresser», Германия) с увеличением в 100 раз.

Все исследования проводили в 3-х повторностях. Достоверность результатов исследований оценивали по критерию Стьюдента при доверительном интервале $\leq 0,05$.

\section{3. РЕЗУЛЬТАТЫ И ОБСУЖДЕНИЕ}

В соответствии с целью исследования на первом этапе были изучены свойства кислого инвертного сиропа, полученного с применением и без применения кавитационной обработки. 
Разработанная во ВНИИКП технология получения кислого инвертного сиропа (IS) заключается в приготовлении сахарного сиропа с долей сухих веществ 78-79\% (вместо 70\% по традиционной технологии) и его гидролиза лимонной кислотой при нагревании без последующей нейтрализации. Образование оксиметилфурфурола предотвращается очень быстрым охлаждением (15 мин) [7]. Приведенная технология позволяет обеспечивать 100\%-ную инверсию сахарозы и получать IS с влажностью $20 \%$, тогда как при традиционном способе количество редуцирующих веществ в инвертном сиропе не превышает 50\% при его влажности $30 \%$.

Для усовершенствования технологии во ВНИИКП был разработан способ получения кислого инвертного сиропа, предусматривающий кавитационную обработку раствора сахара с лимонной кислотой [7]. Кавитацию полученной смеси осуществляли при температуре $85-90{ }^{\circ} \mathrm{C}$ в течение 60 мин. Нагретая смесь с помощью насоса поступает в камеру кавитационной обработки (реактор), где проходит через узкий зазор, образованный стенками трубопровода и ультразвуковым преобразователем, излучающим высокочастотные колебания (рисунок 1).

Необходимо отметить, что смесь изначально содержит большое количество зародышей воздушных пузырьков. Из-за резкого увеличения скорости потока при одновременном значительном снижении давления в области сужения обеспечивается значительный рост газовых пузырьков с накоплением на их поверхности потенциальной энергии. Таким образом, происходит гидродинамическая кавитация, отражающая принцип действия трубки «Вентури». Одновременно под воздействием ультразвукового преобразователя (частота колебаний более 24 кГц, амплитуда 1-3 мкм) происходит акустическая кавитация, обеспечивающая образование волн, где на подъеме волны дополнительно в условиях вакуумирования происходит дальнейший рост пузырьков, а на спуске волны обеспечивается сдавливание пузырьков с одновременной концентрацией энергии. В конечном итоге за счет максимального накопления энергии происходит ее выброс (холодный взрыв) при частичном схлопывании пузырьков воздуха с образованием ударных волн, обеспечивающих максимальное диспергирование частиц твердой фазы.

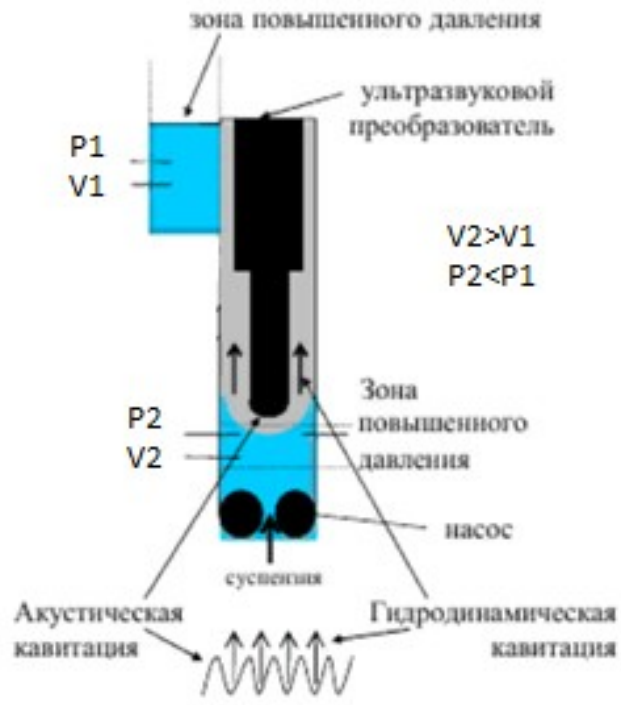

РИСУНОК 1. Принципиальная схема камеры кавитационной обработки инвертного сиропа, где V1, V2 - скорость потока сиропа, P1 и Р2 - давление в потоке [7]

На выходе из реактора происходит снижение скорости потока жидкости до первоначальной, резкое возрастание давления, и схлопывание оставшихся пузырьков воздуха, что сопровождается нагревом реакционной смеси. Описываемые воздействия способствуют максимальному диспергирование частиц до 0,2-0,4 мкм с увеличением их количества и образованием пространственных структур. Этот процесс препятствует седиментации и кристаллообразованию. Инвертный сироп после кавитационной обработки $\left(\mathrm{IS}_{\mathrm{cav}}\right)$ сливают в технологическую емкость и быстро охлаждают до $60{ }^{\circ} \mathrm{C}$ для предотвращения образования оксиметилфурфурола. Полученный таким способом $\mathrm{IS}_{\mathrm{cav}}$ (pH 2-3) может храниться без выпадения кристаллов длительное время (по предварительным исследованиям не менее трех лет). 
Кавитационная обработка инвертного сиропа вызывает существенные изменения его физических свойств. IS ${ }_{\text {саv }}$ является полностью прозрачным раствором, тогда как у IS наблюдается опалесценция.

Исследование плотности IS и IS ${ }_{\text {cav }}$ позволило установить, что кавитационная обработка изменяет плотность инвертного сиропа в сторону ее снижения (Таблица 1). Это впоследствии приводит и к некоторому снижению плотности помадного сиропа с использованием в рецептуре $\mathrm{IS}_{\text {саv, }}$ что находит свое отражение в получении более воздушной и нежной структуры конечного изделия.

ТАБЛИЦА 1. Влияние кавитационной обработки на плотность инвертного и помадного сиропов

\begin{tabular}{|c|c|}
\hline Объект исследования & 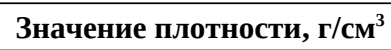 \\
\hline IS & 1560,01 \\
\hline $\mathrm{IS}_{\mathrm{cav}}$ & 1514,47 \\
\hline Помадный сироп, приготовленный на IS & 1429,79 \\
\hline Помадный сироп, приготовленный на IS cav & 1407,43 \\
\hline
\end{tabular}

Кавитационная обработка кислого сахарного сиропа оказывает также влияние на показатель активности воды, характеризующий количество «свободной» влаги, как у полученного инвертного сиропа, так и у помадного сиропа, приготовленного на IS $\mathrm{cav}$ (Таблица 2).

ТАБЛИЦА 2. Влияние кавитационной обработки на показатель активности воды в инвертном и помадном сиропах

\begin{tabular}{|c|c|}
\hline Объект исследования & Значение активности воды \\
\hline IS & 0,537 \\
\hline $\mathrm{IS}_{\mathrm{cav}}$ & 0,576 \\
\hline Помадный сироп, приготовленный на IS & 0,790 \\
\hline Помадный сироп, приготовленный на IS ${ }_{\text {cav }}$ & 0,787 \\
\hline
\end{tabular}

Как видно из приведенных данных в $\mathrm{IS}_{\text {саv }}$ наблюдается некоторое увеличение количества «свободной» влаги, что в дальнейшем создает благоприятные условия для ее адсорбционного и осмотического связывания, способствует удерживанию влаги в процессе хранения помадных конфет и замедлению их черствения. Повышение количества «свободной» влаги в дисперсионной среде также способствует образованию адсорбционных оболочек из дисперсионной среды вокруг максимально возможного количества частиц твердой фазы. В результате повышается относительная подвижность частиц твердой фазы, что подтверждается некоторым снижением плотности IS саv $_{\text {(Таб. 1). }}$

Исследование зависимости коэффициента динамической вязкости IS и IS $\mathrm{cav}_{\text {сv }}$ от скорости деформации (скорость сдвига) показало, что увеличение скоростей деформации в интервале $0,3 \ldots 0,6 \mathrm{c}^{-1}$ приводит к значительному повышению коэффициента динамической вязкости с 8,5 до 23,7 Па·с и с 17,0 до 66,3 Па·с, соответственно (Рисунок 2a). При дальнейшем увеличении скорости деформации в интервале $0,6 . . .5,4 \mathrm{c}^{-1}$ коэффициент динамической вязкости изменяется незначительно, практически оставаясь на постоянном уровне. При повышении скорости деформации выше 5,4 c¹ коэффициент динамической вязкости снижается, что свидетельствует о переходе системы из связнодисперсного в свободнодисперсное состояние.

При этом для $\mathrm{IS}_{\mathrm{cav}}$ при сходном характере кривых отмечен более высокий коэффициент динамической вязкости при всех скоростях деформации, чем для IS. Это свидетельствует о наличии большего количества взаимодействий между твердой и жидкой фазами благодаря уменьшению размера частиц сахара при кавитации и увеличению их количества в 75-80 раз. Также для $\mathrm{IS}_{\mathrm{cav}}$ характерно более резкое снижение коэффициента динамической вязкости с ростом скорости деформации свыше 5,4 $\mathrm{c}^{-1}$.

Исследованы изменения коэффициентов динамической вязкости помадных сиропов до стадии взбивания (охлажденные до $60{ }^{\circ} \mathrm{C}$ ), приготовленных с использованием IS и IS ${ }_{\text {cav }}$ (Рис. 2b). Установлено, что увеличение скоростей деформации в интервале 0,3...0,6 $\mathrm{c}^{-1}$ приводит к повышению коэффициента динамической вязкости помадных сиропов с 187,5 до 388 Па·с и с 477,2 до 605,9 Па·с, соответственно. С повышением скорости деформации более $1,0 \mathrm{c}^{-1}$ коэффициент динамической вязкости резко снижается, что свидетельствует о разрушении структурированной системы. Следует отметить, что при всех скоростях деформации у помадного сиропа на $\mathrm{IS}_{\text {саv }}$ наблюдаются более высокие коэффициенты динамической вязкости. Использование $\mathrm{IS}_{\text {саv }}$ увеличивает число центров кристаллизации и их удельную поверхность, что приводит к увеличению вязкости помадного сиропа. Помадный сироп на $\mathrm{IS}_{\text {саv }}$ имеет более выраженную упруговязкопластичную структуру. 


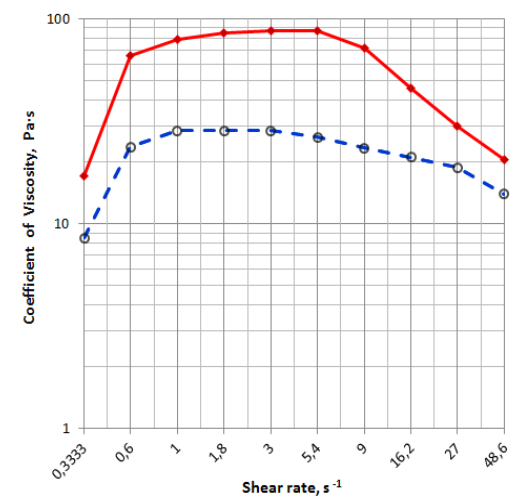

(a)

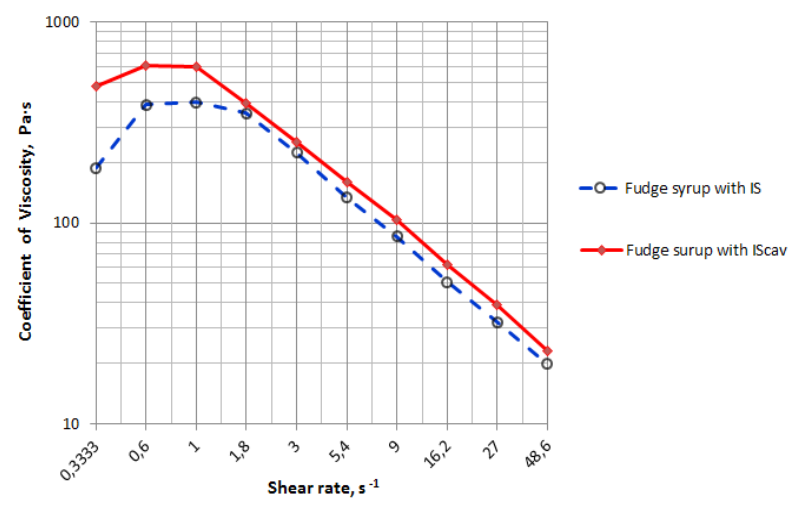

(b)

РИСУНОК 2. Зависимость коэффициента динамической вязкости от скорости деформации: а) для инвертных сиропов;

b) для помадных сиропов

Проведено исследование микроструктуры помадных масс, полученных на крахмальной патоке и инвертных сиропах (Рисунок 3). Использование инвертных сиропов вместо патоки при приготовлении помадных конфет позволяет значительно уменьшить размер образующихся кристаллов. Значительное повышение дисперности помадной массы наблюдается при использовании $\mathrm{IS}_{\text {cav }}$ за счет увеличения в нем количества твердых частиц при уменьшении их размера. Это оказывает свое влияние на качество получаемой помады. Мелкокристаллическая текстура полученной помадки обеспечивала ей в конечном итоге нежную, таящую во рту консистенцию, не утрачивающуюся до конца срока их хранения (35 сут).

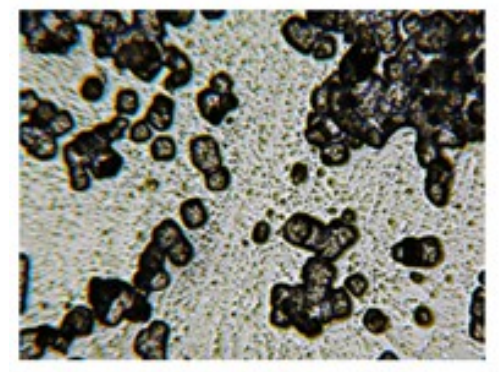

a)

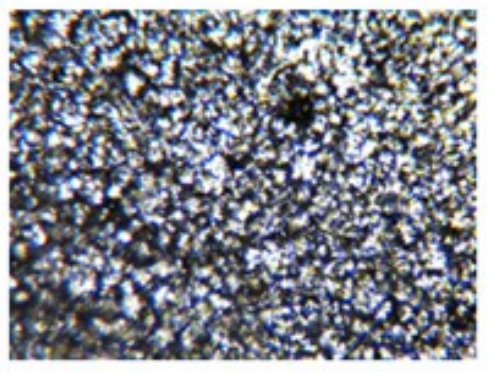

b)

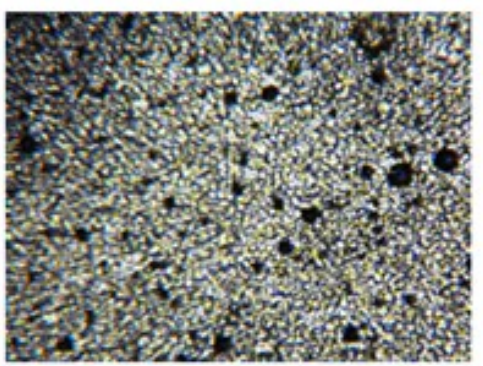

c)

РИСУНОК 3. Микроструктура помадных конфет при увеличении в 100 раз:

а) на патоке; на инвертных сиропах: b) IS; c) IS cav

Повышенное количество редуцирующих веществ в IS и IS $\mathrm{Sav}_{\text {с⿰о }}$ сравнению с крахмальной патокой делает помаду более устойчивой к засахариванию. Было проведено сравнительное изучение потери влаги в процессе хранения помадных конфет, приготовленных на патоке, а также с использованием IS и IS ${ }_{\text {cav }}$ (Рисунок 4). Проведенные исследования позволили установить, что помадные конфеты, приготовленные с использованием инвертных сиропов, лучше удерживают влагу в процессе хранения, что свидетельствует о замедлении протекания в них процессов черствения. Наилучшие результаты достигнуты с использованием $\mathrm{IS}_{\mathrm{cav}}$, в этом случае в конце срока хранения массовая доля влаги в помадных конфетах была выше на $15 \%$ по сравнению с изделиями на патоке.

Исследование показателей микробиологической порчи помадных конфет, полученных на крахмальной патоке, IS и $\mathrm{IS}_{\mathrm{cav}}$, после 35 суток хранения при $5{ }^{\circ} \mathrm{C}$ в картонных коробках (негерметично) без дополнительного внесения пищевых добавок, включая консерванты, показало, что исследуемые показатели находятся в пределах допустимой нормы (Таблица 3).

При этом помадные конфеты, полученные на инвертных сиропах, к концу хранения характеризовались меньшим количеством мезофильных аэробных и факультативно анаэробных микроорганизмов по сравнению с конфетами, выработанными на патоке. 


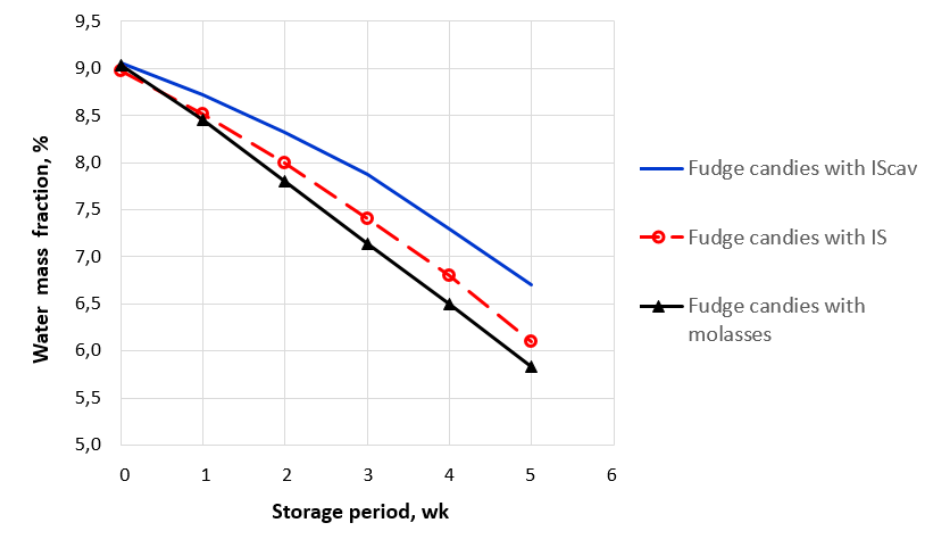

РИСУНОК 4. Зависимость массовой доли влаги от срока хранения помадных конфет

ТАБЛИЦА 3. Показатели микробиологической порчи для помадных масс, выработанных на патоке и инвертных сиропах, после хранения (35 сут, $5{ }^{\circ} \mathrm{C}$ в картонных коробках)

\begin{tabular}{ccccc}
\hline $\begin{array}{c}\text { Помадная масса, } \\
\text { выработанная }\end{array}$ & $\begin{array}{c}\text { Анализируемая } \\
\text { часть изделия }\end{array}$ & КМАФАнМ, КОЕ/г & Плесени, КОЕ/г & Дрожжи, КОЕ/г \\
\hline \multirow{2}{*}{ на патоке } & Корпус & $7 \times 10$ & 10 & 0 \\
& Начинка & $12 \times 10$ & 20 & 0 \\
\hline \multirow{2}{*}{ на IS } & Корпус & $6 \times 10$ & 10 & 0 \\
& Начинка & $10 \times 10$ & 20 & 0 \\
\hline \multirow{2}{*}{ на IS } & Корпус & $5 \times 10$ & 10 & 0 \\
\hline \multirow{2}{*}{ Микробиологические нормативы } & $9 \times 10$ & 50 & 10 \\
безопасности [14] & $5 \times 10^{3}$ & & \\
\hline
\end{tabular}

\section{4. ВЫВОДЫ}

В соответствии с целью исследования на первом этапе были изучены свойства кислого инвертного сиропа, полученного с применением и без применения кавитационной обработки. Изучение органолептических и физико-химических показателей помадных масс, выработанных путем замены крахмальной патоки на кислые инвертные сиропы, полученные с применением и без применения кавитационных воздействий, подтвердило целесообразность такой замены с точки зрения повышения качества помадных конфет. Разработанные во ВНИИКП способы приготовления инвертных сиропов (IS, $\mathrm{IS}_{\text {cav }}$ ) позволяют достигнуть 100\%-ной инверсии сахарозы при влажности сиропов $20 \%$. При этом использование кавитационной обработки на стадии приготовления инвертного сиропа приводит к получению степени дисперсности среды на уровне 0,2-0,4 мкм. Таким образом, IS сау является высококонцентрированной дисперсной системой, что приводит к изменению его физико-химических показателей относительно IS, и как следствие оказывает влияние и на изменение физико-химических показателей помадных сиропов и помадных масс.

Кавитационная обработка сахарного сиропа способствует увеличению количества «свободной» влаги в $\mathrm{IS}_{\text {cav }}$, что в дальнейшем создает благоприятные условия для ее адсорбционного и осмотического связывания и способствует удержанию в процессе хранения помадных конфет. Это было подтверждено исследованием потери влаги в процессе хранения помадных конфет (5 недель), приготовленных с использованием IS и IS $\mathrm{cav}_{\text {cov }}$ Помадные конфеты на IS ${ }_{\text {cav }}$ характеризовались на $15 \%$ более высоким содержанием влаги по сравнению с помадными конфетами на патоке, что свидетельствует о более длительном сохранении потребительских свойств. Повышению количества «свободной» влаги способствует образование адсорбционных оболочек из дисперсионной среды вокруг максимально возможного количества частиц твердой фазы, в результате повышается их относительная подвижность, что приводит к некоторому снижению плотности $\mathrm{IS}_{\mathrm{cav}}$ и помадной массы на его основе.

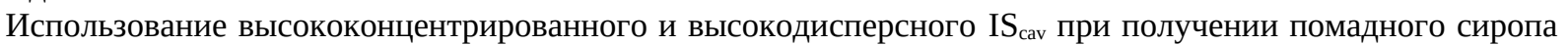
способствует повышению коэффициента динамической вязкости последнего за счет увеличения числа 
центров кристаллизации и их удельной поверхности. Помадный сироп на $\mathrm{IS}_{\mathrm{cav}}$ имеет более выраженную упруговязкопластичную структуру.

Использование при производстве помадной массы IS и IS конечному изделию мелкокристаллическую структуру (особенно на $\mathrm{IS}_{\mathrm{cav}}$ ), нежную, таящую во рту консистенцию. Показатели микробиологической порчи для всех исследованных помадных масс не превышали установленных нормативов.

\section{БЛАГОДАРНОСТИ}

Коллектив авторов выражает благодарность М. А. Талейснику за концептуальную помощь в проведении исследований по получению инвертных сиропов с применением кавитационных воздействий.

\section{СПИСОК ЛИТЕРАТУРЫ}

1. O. Krasulya, V. Bogush, I. Potoroko, L. Tsirulnichenko, S. Khmelev, S. Anandan, Agronomy Research 16(S2), 1396 (2018).

2. I. Potoroko, I. Kalinina, R. Fatkullin, V. Botvinnikova, O. Krasulya, U. Bagale, S. H. Sonawane, Ultrasonics Sonochemistry 48, 463 (2018).

3. L. Qiu, M. Zhang, B. Chitrakar and B. Bhandari, Ultrasonics sonochemistry 68, 105230 (2020).

4. F. Chen, M. Zhang and Ch.-H. Yang, Ultrasonics sonochemistry 63, 104953 (2020).

5. R. Cui and F. Zhu, Ultrasonics sonochemistry 66, 105118 (2020).

6. V. A. Romanova, D. A. Pomogova, I. A. Kirsh, O. V. Beznaeva, O. A. Bannikova, I. S. Tveritnikova, Food Processing Industry 7, 58 (2019).

7. Л. М. Аксенова, В. К. Кочетов, А. Б. Лисицын, К. Н. Никольский, В. А. Панфилов, Н. В. Подхомутов, А. А. Семенова, М. А. Талейсник, Пищевые технологии будущего и нанопреобразования биополимеров (Диапазон-В, Краснодар, 2015).

8. L. M. Aksenova, Food processing industry 11, 50 (2015).

9. О. С. Руденко, М. А. Пестерев, Н. Б. Кондратьев, М. А. Талейсник и А. Е. Баженова, Вестник ВГУИТ 82(4), 163 (2020).

10. М. А. Талейсник, Л. М. Аксенова, А. И. Акимов, И. И. Мизинчикова и М. А. Пестерев, Вестник ВГУИТ 82(4), 17 (2020).

11. О. С. Руденко, М. А. Пестерев, М. А. Талейсник, Н. Б. Кондратьев и А. Д. Сакеллари, Все о мясе 5S, 304 (2020).

12. T. V. Savenkova, M. A. Talejsnik, N. A. Scherbakova, S. Yu. Misteneva and I. I. Mizinchikova, Food Technology 1 (378), 43 (2021).

13. Рецептуры на конфеты и ирис, том 2 (ВНИИКП, Москва, 1986), с. 178.

14. Технический регламент Таможенного Союза ТР ТС 021/2011 «О безопасности пищевой продукции», 74-78 (2011), available at http://24.rospotrebnadzor.ru/s/24/files/links/NormMetodObesp/TehRegTS/98765.pdf 